\title{
Translation and cultural adaptation of Brazilian Detailed Assessment of Speed of Handwriting: conceptual and semantic equivalence
}

\author{
Tradução e adaptação cultural brasileira do Detailed Assessment of \\ Speed of Handwriting: equivalência conceitual e semântica
}

Monique Herrera Cardoso', Sheila Henderson ${ }^{2}$, Simone Aparecida Capellini ${ }^{3}$

\begin{abstract}
Purpose: To perform the translation and cultural adaptation of the Detailed Assessment of Speed of Handwriting (DASH) for the Brazilian population. Methods: (1) Evaluation of conceptual and items equivalence, and (2) Semantic equivalence, including the steps of (2a) Translation, (2b) retranslation, (2c) Review by the committee of judges and (2d) Pre-test. The second step was carried out by two professionals and $2 \mathrm{~b}$ by two other professionals, $2 \mathrm{c}$ was formed by speech therapists, occupational therapists and educators and the $2 \mathrm{~d}$ was carried out with 32 students, four from each age group (9-16 years old). Results: (1) It was found that the concepts and items are equivalent in both cultures (British and Brazilian). In the second stage it was found that two tasks in the original procedure, pangrama classified as a phrase in the English language is used. Therefore, when performing unification of translations, an adjustment was made for the phrase pangrama in Portuguese. In $2 b$ showed that the translation was valid and $2 \mathrm{c}$ was consolidated all versions produced in a single version in Portuguese, which was applied in school. In $2 \mathrm{~d}$ there was acceptance and understanding of the students in the proposed tasks and internal consistency value of 0.701 , others words, satisfactory variability. Conclusion: This procedure can be applied in the Brazilian population, however new studies are being developed with the objective of providing greater reliability and validity of the instrument.
\end{abstract}

Keywords: Handwriting; Assessment; Cross-cultural comparison; Translating; Speech, language and hearing sciences

\begin{abstract}
RESUMO
Objetivo: Realizar a tradução e a adaptação cultural do Detailed Assessment of Speed of Handwriting (DASH) para a população brasileira. Métodos: (1) Avaliação de equivalências conceitual e de itens e (2) Avaliação da equivalência semântica, que envolveu as etapas de (2a) Tradução, (2b) Retradução, (2c) Revisão pelo comitê de juízes e (2d) Pré-teste. A etapa $2 \mathrm{a}$ foi realizada por dois profissionais e a $2 \mathrm{~b}$ por outros dois profissionais; na etapa $2 \mathrm{c}$ foi composto por um comitê de juízes fonoaudiólogas, pedagogas e terapeutas ocupacionais e a $2 \mathrm{~d}$ foi realizada com 32 escolares, sendo quatro de cada faixa etária (de 9 a 16 anos). Resultados: (1) Verificou-se que os conceitos e os itens são equivalentes nas duas culturas (britânica e brasileira). Na etapa 2a, observou-se que, em duas tarefas do procedimento original, foi utilizada uma frase classificada como pangrama na língua inglesa. Diante disso, ao se realizar a unificação das traduções, foi feita uma adaptação da frase para um pangrama na língua portuguesa. Na etapa $2 b$, verificou-se que a tradução foi válida e na $2 c$, todas as versões produzidas foram consolidadas em uma única versão, em português, que foi aplicada aos escolares. Na etapa 2d, constatou-se aceitabilidade e compreensão dos escolares nas tarefas propostas e valor de consistência interna de 0,701 , ou seja, variabilidade satisfatória. Conclusão: O DASH pode ser aplicado na população brasileira. Entretanto, novos estudos estão sendo desenvolvidos, com o objetivo de propiciar maior confiabilidade e validade ao instrumento.
\end{abstract}

Descritores: Escrita manual; Avaliação; Comparação transcultural; Tradução; Fonoaudiologia

Study conducted at the Investigation Learning Disabilities Laboratory at the Speech and Hearing Sciences Department, Faculty of Philosophy and Sciences, Universidade Estadual Paulista "Júlio de Mesquita Filho" - UNESP - Marília (SP), Brazil.

(1) Speech Language Pathology Graduate Program (Masters degree), Universidade Estadual Paulista "Júlio de Mesquita Filho" - UNESP - Marília (SP), Brazil. (2) Department of Psychology and Human Development, Institute of Education, University of London, IOE-London, London WC1H OAA, United Kingdom.

(3) Speech and Hearing Sciences Department, Speech Language Pathology Graduate Program and Education Graduate Program, Universidade Estadual Paulista

"Júlio de Mesquita Filho" - UNESP - Marília (SP), Brazil.

Conflict of interests: No

Authors' contribution: $M H C$ lead researcher, development schedule and research, literature review, data collection and analysis, article writing, submission and procedures of the article; SEH researcher and author of the original procedure in the UK, comparison of the original procedure with the material adapted to Brazil, data analysis, article writing correction; SAC advisor, development schedule and research, data analysis, article writing correction, approval of the final version. Correspondence address: Simone Aparecida Capellini. Av. Hygino Muzzi Filho, 737, Campus Universitario, Marília (SP), Brazil, CEP: $17525-900$.

E-mail: sacap@uol.com.br

Received on: 7/9/2014; Accepted on: 11/11/2014 


\section{INTRODUCTION}

Writing is a cultural invention, in which the earliest forms date to 6 thousand years ago. Has the function of communication, that is, plays the role of spreading the culture and concepts of the humanity ${ }^{(1)}$. According to the literature ${ }^{(2)}$ the written language is defined as a "system of graphic means employed with the purpose of produce acceptable utterances and texts in a given language community".

However, the ability to write is not innate at birth, in other words, was developed only through education ${ }^{(3)}$, being the period of literacy, therefore, a moment that involves cognitive, language and motor skills that require of the students, the capacity to words decoding and motor action suitable for the execution of the motor act of writing, this is, the use of sensory-motors and perceptive components ${ }^{(4)}$.

A recent study ${ }^{(5)}$ identified in children of elementary school, with typical development, that calligraphy develops rapidly during the first series (ages between 6-7 years), evolves around of the 7-8 years and becomes automatic and organized by around of the 8-9 years, becoming a tool available to facilitate the development of ideas of the students, which corroborates other study ${ }^{(6)}$.

However, one study ${ }^{(6)}, 10$ to $30 \%$ of students have difficulty in following the development of writing, and consequently tend to get frustrated when trying to put their ideas on paper, inhibiting their ability to compose texts ${ }^{(7)}$. Continuing difficulties can lead to low self-esteem and less motivated to try, especially when the amount of work enhances with increasing school seriation $^{(8,9)}$.

The difficulties in the acquisition of writing skill can be seen as predictors of learning disabilities ${ }^{(10)}$. The students who have learning difficulties do not acquire strategies and right skills to the development of the writing, and still have low motivation to engage in writing tasks. Already students with dyslexia exhibit production rate writing slower than students without learning difficulties, in other words, produce fewer letters/words per minute in both tasks to write the alphabet as in tasks of textual composition $^{(11,12)}$.

When an individual has adequate intellectual level, receives, in primary education, the appropriate instructions for the acquisition of writing, is submitted to the process of writing practice throughout his academic formation, and even then shows incapacity to produce a written culturally acceptable this difficulty is denominates dysgraphia ${ }^{(13)}$.

According to the DSM-V (Diagnostic and Statistical Manual of Mental Disorders-V), dysgraphia is conceptualized as a "specific learning disabilities with disabilities in written expression," is coded as 315.2 (F81.81). This diagnosis requires the presence of a difficulty with the writing, with persistence for at least 6 months, despite the intervention sessions. In addition, the disorder is characterized by prejudice the individual, resulting in a lower performance than expected for his age, writing ability and difficulties in school performance or profession and in activities of daily life, and you can confirm it by assessment complete clinical and standardized measures of performance ${ }^{(14)}$.

Recent international studies report that the disorder of written expression results in writing skills below that expected for age, related to legibility (quality of letter formation, alignment and spacing of letters and words and sizing of letters) and low speed (rate production) ${ }^{(6,15)}$, showing a important relationship between legibility and the writing speed, this is between the quality and quantity of written ${ }^{(8)}$.

Writing speed is fundamental for example in a moment of realization of exam/tests because the student needs to be able to transfer your ideas to paper while trying to keep up with his thoughts in a determined time ${ }^{(16)}$. However, if the student has to write quickly this could affect the quality/legibility of the text or if he writes more slowly, trying to produce his best letter this could affect negatively the productivity/quantity of writing ${ }^{(17)}$.

Even though there in international literature several studies investigating the handwriting of different optics, such as writing speed, socioeconomics levels and laterality ${ }^{(18)}$, the fatigue effect about the writing production ${ }^{(19)}$, the writing difficulties associated with autism spectrum disorders ${ }^{(20)}$, with attention deficit hyperactivity disorder ${ }^{(21)}$, in Brazil these studies are scarce, making it difficult to establish the profile of calligraphic of the students and, consequently, the investigation of problems related to handwriting.

Given the lack in Brazil, of evaluation instruments specific based on criteria adequate for school age children that measures speed performance and observation aspects of legibility of writing, this study set out to realize the translation and adaptation of the Detailed Assessment of Speed of Handwriting - DASH ${ }^{(22)}$ for the Brazilian population.

The DASH was developed by researchers ${ }^{(22)}$ of the United Kingdom and is a standardized procedure with a representative stratified sample of the country. Has been used to identify children with writing difficulties due to inappropriate speed (dysgraphia), provide a reliable measure of writing speed appropriate to the age and a detailed description of the writing performance as well as control of therapeutic efficacy of intervention programs.

He became popular in the schools that country, because it identifies children with handwriting difficulties and offers an overview of the types of writing tasks expected for a children execute in an educational environment, as currently is the only test that provides scores standardized for children of aged 9 to 16 years $^{(23)}$.

The procedure is composed of five tasks that do not take longer than 30 minutes to be administered, and can be applied in groups or individually. Of the five tasks, four are tasks of writing and one of them is a measure of perceptual-motor competence.

The use of instruments based on criteria of normality is a tool that can assist speech therapists and professionals that working in healthcare and education to evaluate the quality of 
writing to diagnose a delay in the development of writing as well as dysgraphia, and this could help such professionals in the diagnosis of dysgraphia as in differential diagnosis from other motor disorders and of learning that present as manifestation the dysgraphia.

Therefore this study aims to perform the translation and cultural adaptation of the $\mathrm{DASH}^{(22)}$ for the Brazilian population, through of evaluation stages of equivalence conceptual and items, and evaluation of semantic equivalence.

\section{METHODS}

\section{The translation and adaptation of the DASH}

Initially, this study was approved by the Publisher Pearson Assessment, a division of Pearson Education Ltd., which granted the authorization to perform the translation, adaptation and method validation for the Brazilian population.

It was this study was submitted to the Ethics Committee in Research from the Faculty of Philosophy and Sciences, of Universidade Estadual Paulista "Júlio de Mesquita Filho" (UNESP) and obtained the opinion adopted in accordance with the protocol number 0444/2012.

The methodological procedure followed five stages such as proposed in the literature ${ }^{(24)}$, namely: (1) Evaluation of conceptual equivalence and items, and (2) Evaluation of semantic equivalence, including the stages of (2a) Translation, (2b) Retranslation, (2c) Review by committee of judges and (2d) Pre-test.

The stage (1) evaluation and conceptual equivalence of Items examines whether there is relevance and correspondence of the concepts, similarly in the two cultures, British and Brazilian, and was conducted through literature reviews and discussions with members of the Investigation Laboratory Learning Deviations - LIDA - Department of Speech Pathology, UNESP, Marília, forming, thus, a committee of judges, composed by speech therapists, occupational therapists and educators.

The evaluation stage of semantic equivalence (2) evaluated the transfer of meanings between languages in the expectation of obtaining similar effect on respondents from the target population. Is part of the process the attention to the specifics of referential and connotative meaning. This stage was subdivided into four phases.

The translation stage (2a) was carried out by two professionals, one formed in letters with specialization in English and the other in translation with post-graduation in English language. Both had knowledge of the purpose of the study and realized translations of the original procedure in English for the Portuguese, independently, producing two translations.

After this step, the two translations were compiled into one, which was delivered to the other two translators to perform the stage of Retranslation (2b), this is the translation back to the original language (back-translation). One of the translators was Master in Computer Science in the area of Software Engineering, and English speaker to reside in New Zealand two years, and the other with graduated in Translation with Postgraduate in Text Revision. These have not received information about the concepts and purposes of the research.

The two versions back-translated for English, the compiled version in Portuguese and the original procedure were analyzed by Committee of Judges (stage 2c) for the evaluation of the ite$\mathrm{ms}$ as the semantic equivalence (meaning of words), idiomatic (formulation of colloquial expressions equivalent to the origin language), cultural (terms and everyday situations different between cultures) and conceptual (words that have different cultural meanings) and composed the adapted version of the DASH, to be subjected to pre-test (2d). This stage (2d) had the purpose to assure that the adapted version is equivalent to the original version, in addition to detecting errors, evaluating not only the quality of the translation, as well as the practical aspects of its application.

\section{Pilot study participants}

The adapted version of the DASH was applied to 32 students, 16 female and 16 male, when four in each age group (from 9 to 16 years old).

To participate in this stage the students have delivered the Consent Term signed by parents or guardians, could not present annotations regarding the presence of sensory impairment, motor or cognitive, hearing complaints, visual or motor constant in their school records.

Even as a selection criterion a cognitive assessment test was applied (Raven Progressive Matrices), to the exclusion of cases of mental retardation. Was also carried out a survey with pedagogical coordinators on students who had school complaint, psychoaffective problems or even speech therapy diagnostics (eg, autism, ADHD, dyslexia, etc.), and in these cases excluded from the sample data from this study.

The selection of these students was realized by call list, being invited to attend the first two boys and first two girls from of the list. They should follow the inclusion criteria, as described above and having ages according to seriation school (Chart 1). If the student did not fit these selection criteria, the next name on the list was invited to participate.

The data collection with the students was realized in groups of four students in a single session, not exceeding the time 50 minutes duration.

\section{The Detailed Assessment of Speed of Handwriting (DASH)}

The procedure is composed of five tasks, in four tasks is writing and one of these is a measure of perceptual-motor competence, this is, does not involve linguistic aspects of the 
Chart 1. Age corresponding to seriation school

\begin{tabular}{|c|c|}
\hline Seriation school & Age \\
\hline $4^{\text {th }}$ grade of elementary school & $\begin{array}{c}9 \text { years to } 9 \text { years and } \\
11 \text { months }\end{array}$ \\
\hline $5^{\text {th }}$ grade of elementary school & $\begin{array}{l}10 \text { years old to } 10 \text { years old and } \\
11 \text { months }\end{array}$ \\
\hline $6^{\text {th }}$ grade of elementary school & $\begin{array}{l}11 \text { years old to } 11 \text { years old and } \\
11 \text { months }\end{array}$ \\
\hline $7^{\text {th }}$ grade of elementary school & $\begin{array}{l}12 \text { years old to } 12 \text { years old and } \\
11 \text { months }\end{array}$ \\
\hline $8^{\text {th }}$ grade of elementary school & $\begin{array}{l}13 \text { years old to } 13 \text { years old and } \\
11 \text { months }\end{array}$ \\
\hline $9^{\text {th }}$ grade of elementary school & $\begin{array}{l}14 \text { years old to } 14 \text { years old and } \\
\qquad 11 \text { months }\end{array}$ \\
\hline $1^{\text {st }}$ year high school & $\begin{array}{l}15 \text { years old to } 15 \text { years old and } \\
11 \text { months }\end{array}$ \\
\hline $2^{\text {nd }}$ year high school & $\begin{array}{c}16 \text { years old to } 16 \text { years old and } \\
11 \text { months }\end{array}$ \\
\hline
\end{tabular}

language. We applied the five tasks proposed in DASH, as described below:

Task 1 - Copy best: The student should write, without interruption, a determined sentence, classified as pangram (sentence containing all the letters of the alphabet) with your best handwriting, for two minutes, that is, copy the phrase as often as he managed, within two minutes.

Task 2 - Alphabet writing: The student was oriented to write the alphabet, in order, with cursive letters lowercase, continuously for one minute. On reaching the letter " $z$ " and there was still time, the school should start the alphabet until the end of time.

Task 3 - Copy fast: The student should write the same sentence of the first task, as soon as possible, but in a legible form, continuously for two minutes, that is, copy the phrase as often as he managed, within two minutes.

Task 4 - Graphic speed: It is a task optical that required the student to make a series of " $\mathrm{X}$ " within circles, for a minute, focusing more on fine motor coordination, this is, the aspects of precision to make a mark.

Task 5 - Free writing: The student was requested the elaboration of an wording on the theme "My Life" for 10 minutes, however, the every two minutes the student should make a mark in the text, which allows us to monitor the frequency production of the children in different periods of time.

The every explanation of the tasks the students could question if not understood what was being asked, and at the end of task five they were asked about the difficulty to realize the proposed activity and if there was any suggestion to improve the comprehension of the instrument.

At the end of all these stages, a new meeting with the committee of judges was realized in order to verify possible changes and, therefore can complete the stage of translation and adaptation of the DASH.

\section{Statistical analysis}

The analysis of internal consistency of translated and adapted version of the DASH was assessed using Cronbach's Alpha coefficient, with threshold of $0.70^{(25)}$ through the Statistical Package for Social Sciences (SPSS - version 18).

\section{RESULTS}

For the first stage of the translation and transcultural adaptation of the DASH - Evaluation of conceptual equivalence and items - after literature reviews and discussions with members of the committee of judges was found that the concepts and items used in the original procedure are equivalent in the two cultures (British and Brazilian).

In the second stage (2a) - Translation - it was found that two tasks of the original procedure (task 1 and 3 ) was used a phrase classified as pangram in English language, this is, a phrase (with the smallest number of letters possible) composed of all the letters of the alphabet - The quick brown fox jumps over the lazy dog. Even at this stage, it was observed that, in task 2 (alphabet writing), lowercase letters were required, however, without differentiation between cursive and printed letters.

The two Portuguese versions were analyzed by the researcher, and when performing compilation of translations in a single version, was made the adaptation of the sentence to one pangram in Portuguese language - One day Max played soccer with his neighbor Pedro, thus producing a version of the DASH in Portuguese. Although the letters K, W and Y were inserted in the alphabet Brazilian, in conversation with the committee of judges was defined a pangram sentence without these letters, as they are part of foreign words or proper names, and therefore are not used regularly day-to-day of students.

For task 2, the committee of experts opted to choose a specific type of letter and consequently the orientation given to the school was changed to "write the alphabet, in order, with cursive and lowercase letters, for one minute." The school could choose to write the letters one by one, in isolation, or rather write them joined together

This version compiled and adapted to Brazilian Portuguese was to stage $2 b$ - Retranslation - necessary procedure to check the validity of the translation and found that there were no discrepancies in meaning and content between the original instrument and the instrument re-translated to English, with exception of the modification of the pangram sentence and orientation of Task 2 (alphabet writing).

The analysis by the committee of judges - stage $2 \mathrm{c}$, formed by speech therapists, educators and occupational therapists, was through review of all versions (translations, compiled version and back-translations) compared to the original procedure and confirmed that the only adaptation to be made was the modification of the sentence for pangram in Portuguese language and the choice of cursive in task 2 . At the end of this analysis 
was finalized the adapted version of the DASH, to be subjected to pre-testing $(2 \mathrm{~d})$.

In the pilot study - step $2 \mathrm{~d}$ - the students were asked about the possible difficulties to understand and perform the proposed tasks and all reported complete understanding. Therefore, this step revealed easy applicability of the instrument, due to the acceptability and understanding of the students in the proposed tasks, there is no need for adjustments final semantic in the adapted version of the procedure.

The Cronbach Alpha was calculated for the procedure and verified satisfactory internal consistency, as the value found was 0.701 .

\section{DISCUSSION}

When applying a procedure developed in one cultural context to another context it is necessary an evaluation of equivalence between the original procedure and its adapted version $^{(26)}$, due to cultural differences in definitions, beliefs and behaviors among many populations.

For certification that the instrument is understandable to all members of the population for which it is intended ${ }^{(27)}$, you must perform the cross-cultural adaptation, emphasizing the semantic equivalence of the terms and not in the literal equivalence. Translation step of a procedure requires linguistic care, because terms may have different meanings and specificities inherent to each language ${ }^{(27)}$. Therefore, the use of four translators was extremely useful for the construction of the Portuguese version of DASH, since all versions could be confronted and discussed with the committee of experts.

According to the literature the group of judges should be formed by experts in the field of knowledge about the theme ${ }^{(24)}$, so the judges were speech therapists, occupational therapists and educators, that is, professionals who work with handwriting and analysis of handwritten of students, which facilitated discussions for the best composition of the adapted version to be submitted to a pre-test.

The option of font (cursive or printed) was necessary, because the motor and cognitive requirement between them is different. Defined by the cursive due to the fact that this form of writing is characterized by connections between the letters of syllables to form and, consequently, of the connections between the syllables to form words. These connections allow the school to write with speed and force them to think about all the details of writing, contributing to their cognitive development and helping to improve their skills related to attention $^{(28)}$.

The writing in cursive, the second study ${ }^{(29)}$, being connected and flowing, provides benefits to school, because, after the production of a letter, do not need to lift the pencil to write the following letter, which consequently reduces the spacing between words, favoring therefore greater rhythm and writing speed $^{(30)}$.
The application of the instrument in the target population (stage of pre-test) followed exactly the amount of students requested in specialized literature in translation and adaptation of procedures ${ }^{(24)}$, that is between 30 to 40 students. This step was important, not only for permitting the verification of understanding of the items, but also allow for discussion of the viability of application of the instrument in the Brazilian population who is intended the DASH, since they were selected educational levels and age groups corresponding the original procedure and found value in a satisfactory internal consistency.

The Portuguese version of the Detailed Assessment of Speed of Handwriting satisfied the criteria and conceptual equivalence of items and semantic equivalence, however, in order to finalize the process of adaptation to Brazilian culture, yet are necessary the stages of Operational equivalence and measurement. In particular, it is recommended to construct validation, as there is no a reference instrument (gold standard) to evaluate the speed and legibility of writing in our population.

\section{CONCLUSION}

For a research instrument from another country to be used reliably for the Brazilian population, it is necessary to perform of the translation and transcultural adaptation. In this study we performed the first stages towards the elaboration of the Brazilian version of the Detailed Assessment of Speed of Handwriting, this is conceptual equivalence of items and semantic equivalence, and from this we can conclude that this procedure can be applied in the Brazilian population. However a new study is being developed with the number of students equal to the original procedure with the objective of maintain the operational characteristics of the original procedure, providing greater reliability and validity of the instrument, comparing them with those found in the original instrument. For future studies, we may have an evaluation instrument available for raise useful information and complementary to elaborate intervention programs with writing difficulties.

\section{ACKNOWLEDGEMENTS}

For the Publisher Pearson Assessment, a division of Pearson Education Ltd and Fundação de Amparo à Pesquisa do Estado de São Paulo (FAPESP), process number 2012/04513-0.

\section{REFERENCES}

1. Planton S, Jucla M., Roux F-E, Demonét J-F. The "handwriting brain": A meta-analysis of neuroimaging studies of motor versus orthographic processes. Cortex. 2013;49(10):2772-87. http://dx.doi. org/10.1016/j.cortex.2013.05.011

2. Scliar-Cabral L. Princípios do sistema alfabético do português do Brasil. São Paulo: Contexto, 2003. 
3. Erdogan T, Erdogan O. An analysis of the legibility of cursive handwriting of prospective primary school teachers. Procedia Soc Behav Sci. 2012:46:5214-8. http://dx.doi.org/10.1016/j.sbspro.2012.06.412

4. Capellini SA, Souza AV. Avaliação da função motora fina, sensorial e perceptiva em escolares com dislexia do desenvolvimento. In: Sennyey AL, Capovilla FC, Montiel JM. Transtornos de aprendizagem: da avaliação à reabilitação. São Paulo: Artes Médicas; 2008. p. 55-64.

5. Overvelde A, Hulstijn W. Handwriting development in grade 2 and grade 3 primary school children with normal, at risk, or dysgraphic characteristics. Res Dev Disabil. 2011;32(2):540-8. http://dx.doi. org/10.1016/j.ridd.2010.12.027

6. Feder KP, Majnemer A. Handwriting development, competency, and intervention. Dev Med Child Neurol. 2007;49(4):312-7. http://dx.doi. org/10.1111/j.1469-8749.2007.00312.x

7. Medwell J, Wray D. Handwriting: a forgotten language skill? Lang Educ. 2008;22:34-47. http://dx.doi.org/10.2167/le722.0

8. Shen I-H, Lee T-Y, Chen C-L. Handwriting performance and underlying factors in children with Attention Deficit Hyperactivity Disorder. Res Dev Disabil. 2012;33(4):1301-9. http://dx.doi. org/10.1016/j.ridd.2012.02.010

9. Martins MR, Bastos JA, Cecato AT, Araujo ML, Magro RR, Alaminos V. Screening for motor dysgraphia in public schools. J Pediatr (Rio J). 2013;89(1):70-4. http://dx.doi.org/10.1016/j.jped.2013.02.011. 10. Fin G, Barreto DBM. Avaliação motora de crianças com indicadores de dificuldades no aprendizado escolar, no município de Friburgo, Santa Catarina. Unoesc \& Ciência - ACBS. 2010;1(1):5-12.

11. Graham S, Harris KR. Almost 30 years of writing research: making sense of it all with the wrath of khan. Learn Disabil Res Pract. 2009;24:58-68. http://dx.doi.org/10.1111/j.1540-5826.2009.01277.x

12. Sumner E, Connelly V, Barnett A. Children with dyslexia are slow writers because they pause more often and not because they are slow at handwriting execution. Read Writ. 2012;26(6):991-1008. http://dx.doi. org/10.1007/s11145-012-9403-6

13. Rosenblum S, Aloni T, Josman EN. Relationships between handwriting performance and organizational abilities among children with and without dysgraphia: a preliminary study. Res Dev Disabil. 2010:31(2):502-9. http://dx.doi.org/10.1016/j.ridd.2009.10.016

14. American Psychiatric Association. Diagnostic and statistical manual of mental health disorders. 5th ed. Arlington: American Psychiatric Association; 2013.

15. Kushki A, Schwellnus H, Ilyas F, Chau T. Changes in kinetics and kinematics of handwriting during a prolonged writing task in children with and without dysgraphia. Res Dev Disabil. 2011;32(3):1058-64. http://dx.doi.org/10.1016/j.ridd.2011.01.026

16. Prunty MM, Barnett A, Wilmut K, Plumb MS. Handwriting speed in children with Developmental Coordination Disorder: Are they really slower? Res Dev Disabil. 2013;34(9):2927-36.
17. Burger DK, McCluskey A. Australian norms for handwriting speed in healthy adults aged 60-99 years. Aust Occup Ther J. 2011;58(5):355-63. http://dx.doi.org/10.1111/j.1440-1630.2011.00955.x

18. Summers J, Catarro F. Assessment of handwriting speed and factors influencing written output of university students in examinations. Aust Occup Ther J. 2003;50(3):148-57. http://dx.doi.org/10.1046/j.14401630.2003.00310.x

19. O’Mahony P, Dempsey M, Killeen H. Handwriting speed: duration of testing period and relation to socio-economic disadvantage and handedness. Occup Ther Int. 2008;15(3):165-77. http://dx.doi. org/10.1002/oti.255

20. Fuentes CT, Mostofsky SH, Bastian AJ. Children with autism show specific handwriting impairments. Neurology. 2009;73(19):1532-7. http:// dx.doi.org/10.1212/WNL.0b013e3181c0d48c

21. Frings M, Gaertner K, Buderath P, Christiansen H, Gerwig M, HeinKropp C, et al. Megalographia in children with cerebellar lesions and in children with attention deficit/hyperactivity disorder. Cerebellum. 2010;9(3):429-32. http://dx.doi.org/10.1007/s12311-010-0180-y

22. Barnett AL, Henderson SE, Scheib B, Schulz J. Detailed Assessment of Speed of Handwriting (DASH). Oxford: Person, 2007.

23. Barnett AL, Henderson SE, Scheib B, Schulz J. Handwriting difficulties and their assessment in young adults with DCD: extension of the DASH for 17-to 25-year-olds. J Adult Dev. 2001;18:114-21. http:// dx.doi.org/10.1007/s1080-011-9121-3

24. Reichenheim ME, Moraes CL. Operationalizing the crosscultural adaptation of epidemiological measurement instruments. Rev Saúde Púb. 2007;41(4):665-73. http://dx.doi.org/10.1590/S003489102006005000035

25. Nunnally JC. Psychometric theory. 2nd ed. New York: McGraw-Hill; 1978.

26. Sardinha A, Levitan MN, Lopes FL, Perna G, Esquivel G, Griez Ej, et al. Translation and cross-cultural adaptation of the Habitual Physical Activity Questionnaire. Rev Psiquiatr Clín. 2010;37(1):16-22. http:// dx.doi.org/10.1590/S0101-60832010000100004

27. Serralta FB, Cony F, Cenbranel Z, Greyson B, Szobot CM. Equivalência semântica da versão em português da Escala de Experiência de Quase-Morte. Psico-USF. 2010;15(1):35-46. http://dx.doi.org/10.1590/ S1413-82712010000100005

28. Gunes F. Niçim bitisik egik yazi bilim ve aklin aydinliginda egitim. Dergisi. 2006;71:17-19.

29. Deuel RK. Developmental dysgraphia and motor skills disorders. J Child Neurol. 1995;10(Suppl 1):S6-8.

30. Almeida PHTQ, Sorensen CBS, Magna L, Cruz DMC, Ferrigno ISV. Avaliação da escrita através da fotogrametria: estudo da preensão trípode dinâmica. Rev Ter Ocup USP. 2013;24(1):38-47. http://dx.doi. org/10.11606/issn.2238-6149.v24i1p38-47 